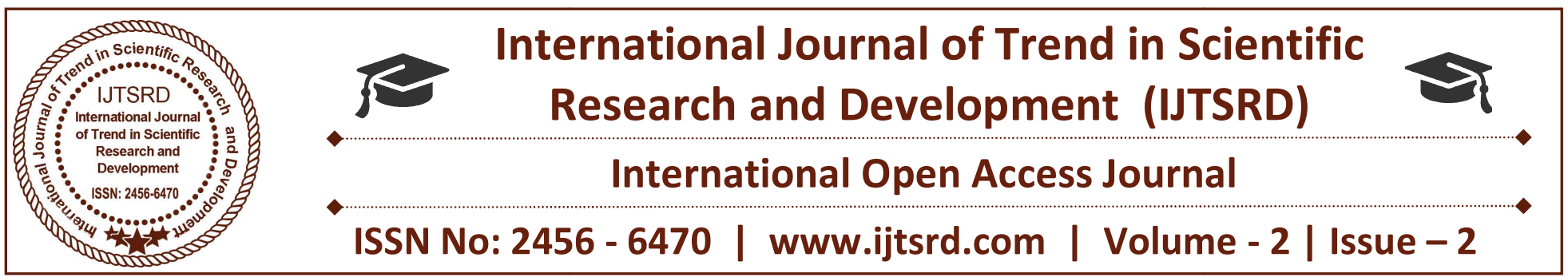

\title{
Quick Response Based Smart Ration System
}

\section{Prof. Pragati Mahale, Divya Prabhu, Kiran Nanaware, Komal Popli, Siyona Navgire}

Department of Information Technology

AISSMS's IOIT, Pune, Mahashtra, India

\section{ABSTRACT}

Ration card is used to get subsidized food for poor people. It comes in three different colors, those are yellow, white and saffron. The current rationing system is not well organized and so many illegal activities takes place. Government don't get correct information of how much quantity of ration is being given to customer and how much is left in the ration shops. Shopkeepers makes manual entry, so he can make false entry and government will be unaware of it. To eliminate these we have proposed QR code based Smart Ration System. QR code will be ration card of user and it will contain basic details of customer. While going to ration shop, customer will have to carry QR code. This QR code will be scanned by the shopkeeper and after scanning that customer details will be displayed on the screen. To make further purchase of rations, shopkeeper will have to enter the OTP which will be sent to customer registered number for verification. Quantity taken by the customer will be deducted from shopkeeper and customer database automatically. So government will have clear details of how much ration stock is left in $s \neg \neg$ hop. Shopkeeper will not be able to perform unfair practices. An SMS will be sent to the customer after buying ration.

Keywords: $Q R, S M S, O T P$

\section{INTRODUCTION}

Ration cards is useful documents for poor people to purchase essential commodities from fair price shop. It is also used as an address and identity proof.

According to the annual income of people, they are being allocated ration card accordingly. Current ration card system has some limitations. Many times shopkeepers also illegally provide ration under names of illegible, dead people or duplicate names from other areas. They also tend to show fake quantities of goods available in shop to the higher authority, as they enter details manually. It is a slow process because of which people will have to wait in a queue for long time. Also lot of people misuse it and hold ration card to buy rations even though they can afford from open market. Our proposed system QR code based Smart Ration System can be used to solve these problems. The main focus here is to avoid forgery and to eliminate manual methods. Customer have to register by filling form and after submitting form QR code will be sent to their emailed. QR code will contains customer details in encrypted format, so no one except shopkeeper can scan that QR code. Normal QR code scanner cannot encrypt these details, as the information will be encrypted using AES algorithm. For purchasing ration customer has to show QR code to the shopkeeper. He will scan QR code and customer details will be displayed on the screen. After this an OTP will be send to the customer mobile which will be active for some time. Shopkeeper have to enter these OTP to make further purchase. Shopkeeper and customer database will be deducted automatically after purchase. So government will be getting correct information about the stocks.

Customers will also be informed about the purchased ration through the SMS which will be send to their 
registered mobile number. Customer can update his details by logging into the system by using username and password which will be set by the customer during registration.

\section{RELATIVE WORK}

Sana Q., Dr. R. Dube [1] This Smart Ration Card System uses a Smart Ration Card and Finger print authentication. The user has to swipe the Ration Card. UID is checked with the UID in the database to check whether the card is valid. If card is the valid, the finger print authentication is done to check if the user is valid. If valid, the purchase is allowed and the required amount of grocery is allotted to the customer.

[2]. http://www.linkaadharcard.com/link-aadhaarcard-with-ration-card/

Here, the user needs to enter the benefit type, address details, Aadhaar Card number and correct contact number to receive the OTP. A government officer will verify this information after the request is submitted.

Vikram Singh et. [3] This system uses barcodes. It consists of two databases, one for storing user's personal information and the other for storing the purchase details. If the details in the barcode match with the details in the database, the user is validated and purchase is allowed. Every item in the FPS contains a specific code. The quantity of item purchased is calculated using that code.

S. Kangasubaraja et. [4] This Smart Ration Card consists of the photo of the family head, a thumb impression and family member details. The thumb impression is also stored in the database. The thumb impression is used for authenticating the customer. Also, The Government and local database is updated according to the information of goods supply. For a new member to be added, the user has to go to the Government office.

K. Bala Karthik [5] RFID is used in this system. The RFID is read and the ID is sent to the server which retrieves the registered phone number of customer. A random password is sent to this phone number for authentication.

A. N. Madur [6] Password and RFID is used in this system. Balance is checked and the system opens the valve if the balance is sufficient. The valve acts as an outlet for the grains and places them on a weight sensor. When entered amount equals the measured quantity, the valve will be closed and the database is updated.

\section{PROPOSED SYSTEM}

The proposed Smart Ration Card System is based on QR Code. An AES encrypted QR Code is used for security purposes. Along with the QR Code, One Time Password is also used for two-factor Authentication. The users will be sent by e-mail a downloadable QR Code containing all their personal information in an encoded format after registration. This QR Code and other details like residential address, phone number, annual income, etc. of the customer will be stored in the database can also be used as identity proof for various purposes. The QR Code will then have to be scanned by registered shopkeepers using a special scanner for reading the encoded data. To be able to further buy groceries, an OTP will be sent on the user's registered mobile number. This will be the second factor of authentication. On entering and verification of the OTP, the user will be permitted to buy grocery. A quota will be assigned to every user by the admin on the basis of number of family members mentioned and the annual income. User will have to buy his/her monthly grocery within the limits of the assigned quota. Required amount by user should be less than or equal to the quota allotted to the user. After purchase, the bought amount will automatically be deducted from the quota in the database and the user will be sent a purchase receipt.

Along with this, the system will also maintain the record of stock supply at all levels from the Government to the states, to the districts and further to every registered shop. Each shopkeeper will have to register their shops to the system. The government will supply the groceries on the basis of number of shops in every area. 


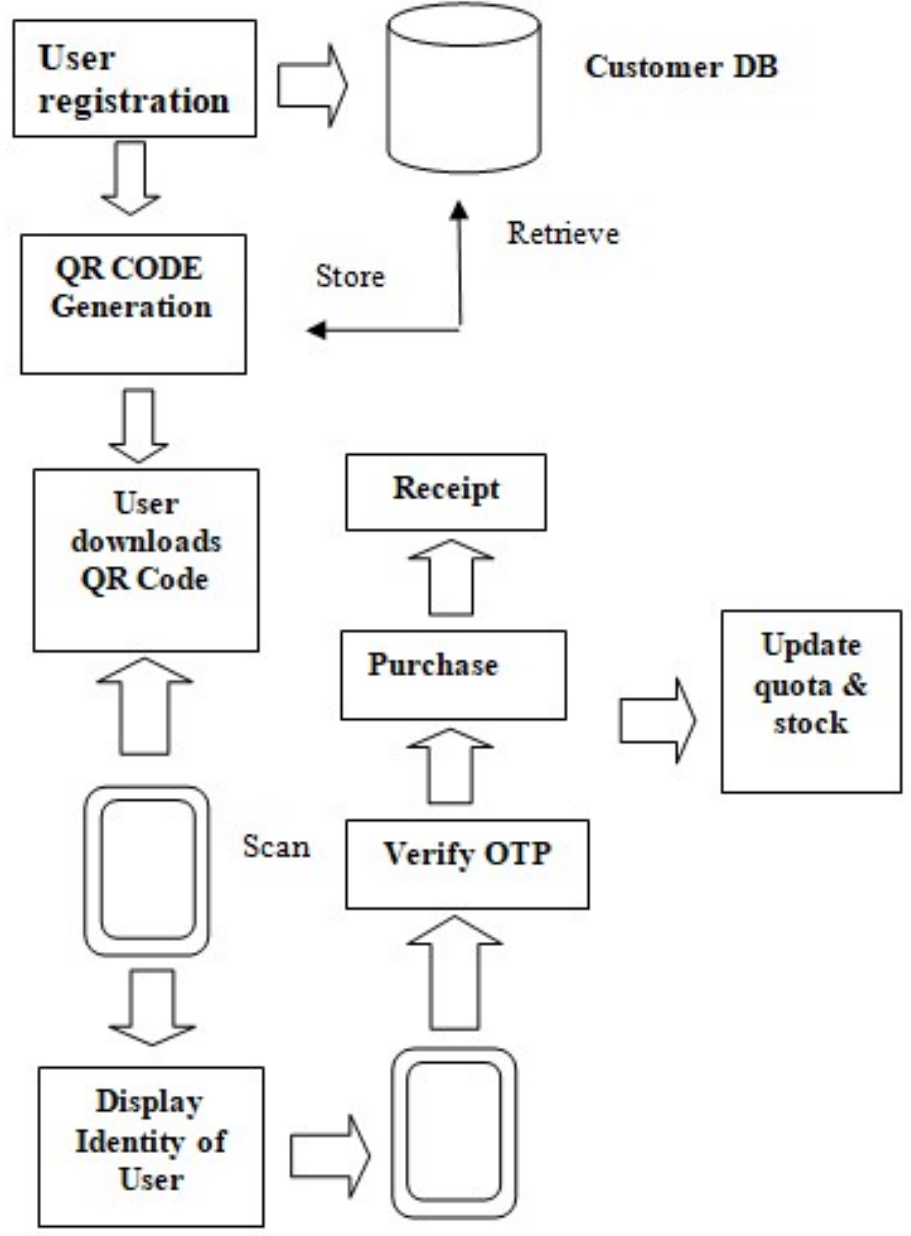

FIG 1. QR CODE AND OTP BASED RATION CARD SYSTEM ARCHITECTURE.

\section{EXPECTED RESULTS}

The expected result of this System is that the system it should be able to generate QR Code successfully. It should automatically deduct information from shopkeeper and customer databases. Customer verification should be done by sending OTP to the registered customer. If the selected grocery items is exceeded the limit then an error message should be displayed. Customer should receive SMS after purchasing ration.

\section{CONCLUSION}

With various disadvantages of existing system, this proposed system is simpler, cost effective and more efficient. This paper explains the proposed system working which uses Quick response code and one time password.

\section{REFERENCES}

1) Sana A. Qader Perampalli, Dr. R.R. Dube, "Smart Card based e-Public Distribution System," International Journal of Advanced Research in Computer and Communication Engineering, Vol. 5, Issue 5, May 2016.

2) http://www.linkaadharcard.com/link-aadhaarcard-with-ration-card/

3) Vikram Singh, VellankiAamani, Booreddy Mounika, "SMART RATION CARD, " Journal of Global Research in Computer Science, Volume 4, No. 4, April 2013.

4) S.Kanagasubaraja, K. Arul Ganesh, G. Mohesh Viswanath, R. Prabha, "Biometric Device Using Smart Card In Public Distribution System," IRF International Conference, 29th March 2015.

5) K.Balakarthik, "Cloud-Based Ration Card System using RFID and GSM Technology2, Issue," vol. 4, Apr 2013.

6) A.N.Madur, Sham Nayse, "Automation in Rationing System Using Arm 7," International journal of innovative research in electrical, electronics, instrumentation and control engineering, vol.1, Issue Jul 2013. 